Article

\title{
Aerobic Oxidation of Benzyl Alcohol on a Strontium-Based Gold Material: Remarkable Intrinsic Basicity and Reusable Catalyst
}

\author{
Karla Patrícia R. Castro ${ }^{1}$, Marco Aurélio S. Garcia ${ }^{1}$, Wiury C. de Abreu ${ }^{1,2}$, \\ Samuel Anderson A. de Sousa ${ }^{1}$, Carla Verônica R. de Moura ${ }^{1}$, Jean Cláudio S. Costa ${ }^{1}$ and \\ Edmilson M. de Moura ${ }^{1, *}$ \\ 1 Chemistry Department, Federal University of Piauí, Teresina 64049-550, PI, Brazil; \\ karlaribeirocastro@gmail.com (K.P.R.C.); marcoasuller@gmail.com (M.A.S.G.); \\ wiury.abreu@ifma.edu.br (W.C.d.A.); samuelsousa@ufpi.edu.br (S.A.A.d.S.); carla@ufpi.edu.br (C.V.R.d.M.); \\ jean-cla@iq.usp.br (J.C.S.C.) \\ 2 Federal Institute of Maranhão, Buriticupu 65393-000, MA, Brazil \\ * Correspondence: mmoura@ufpi.edu.br; Tel.: +55-869-9432-4080
}

Received: 5 January 2018; Accepted: 9 February 2018; Published: 15 February 2018

\begin{abstract}
The development of stable and active gold catalysts has arisen as a significant strategy for oxidation of alcohols. Nano-size PVA-stabilized gold nanoparticles immobilized on $\mathrm{Sr}(\mathrm{OH})_{2}$ by colloidal deposition presented high catalytic activity for benzyl alcohol oxidation. In $2.5 \mathrm{~h}, 2 \mathrm{bar}$ of $\mathrm{O}_{2}$ and without extra-base addition, the calcined support reached $54.6 \%\left(100{ }^{\circ} \mathrm{C}\right)$ and $67.4 \%\left(140{ }^{\circ} \mathrm{C}\right)$ of conversion, presenting the remarkable and unexplored intrinsic basicity that strontium-based materials retain. With sub-stoichiometric $\mathrm{K}_{2} \mathrm{CO}_{3}$ adding, under the same catalytic conditions, the catalyst conducted the reaction with similar activity, but with excellent reusability in the process, without any gold leaching. We investigated the influence that the support synthesis method and the solvent used for the NPs stabilization have on the oxidation activity. The produced materials were fully characterized by XPS, Rietveld refinement, and TEM.
\end{abstract}

Keywords: alcohol oxidation; gold catalyst; strontium hydroxide

\section{Introduction}

Heterogeneous catalysts play an important role globally, not only with respect to an economic perspective, but they also are paramount to ensuring structure for the prosperity of society as a whole. Materials, foodstuffs, and pharmaceuticals, which are essential for the wellbeing worldwide, have intermediates that are heterogeneously catalyzed products. Catalysis by gold-based materials has become one of the most studied topics in chemistry for a wide range of reactions. Studies performed by Prati, Rossi, and partners demonstrated [1-3] for the first time that supported gold nanoparticles (NPs) can be used to oxidase alcohols, diols, and polyols in presence of a base, as it was originally considered to be essential for the substrate hydrogen abstraction [4]. However, the requirement of base addition to achieve satisfactory rates may be in some cases considered a restriction to the use of Au NPs catalysts, since side reactions or catalyst damage may occur [5]. In order to avoid any drawbacks, the combination of Au NPs with a second metal from the platinum group has received attention as an alternative to monometallic gold-based catalysts, for which base employment is typically required [5-7]. Although this strategy is actually interesting, one may notice that the synthesis of a catalyst using two noble metals may cause a price augmentation or the necessity of more steps for its final production. Thus, some work has been done to understand and use highly available basic supports, such as alkaline earth metal oxides and hydroxides, not just for its intrinsic basicity, but also due to the interaction of 
$\mathrm{Au}$ NPs with the solid [8]. Charge-density models [9] that predict the strength of oxygen Lewis basic sites in such oxide catalysts decrease in the order of $\mathrm{O}^{2-}>\mathrm{OH}^{-}>\mathrm{H}_{2} \mathrm{O}>\mathrm{H}_{3} \mathrm{O}^{+}$; nevertheless, the most explored materials as support for $\mathrm{Au}$ NPs for alcohol oxidation are $\mathrm{MgO}$ and $\mathrm{Mg}(\mathrm{OH})_{2}$, without the addition of extra base in the reaction medium $[10,11]$. While these materials may be used with excellent activity and selectivity, and there is a large body of literature dealing with magnesium compounds as support (or as base additives in some catalytic systems) [12-19], the use of strontium-based materials is somehow neglected. To the best of our knowledge, $\operatorname{Sr}(\mathrm{OH})_{2}$ was not used as a support for Au NPs oxidation reactions, or its hydroxide phase was not considered in such experiments. Few examples showing $\mathrm{SrO}$ applications as a support presented no further discussion on its real function $[20,21]$. Studying aldol addition of acetone, Zhang et al. performed TPD measurements of alkaline earth metal oxides under the same reactive conditions. Data suggested that the strength of the basic sites of SrO are higher than the observed for $\mathrm{MgO}$ [22], the same conclusion achieved by Kabashima et al. when studying double bond isomerization of 5-vinylbicyclo[2.2.1] hept-2-ene [23]. In open air, strontium oxide reacts with water vapor, converting to strontium hydroxide, making it difficult to retain this compound in its oxide form. However, although metal hydroxides are weaker bases than the oxides, the strength order suggested $\mathrm{Sr}(\mathrm{OH})_{2} \cdot 8 \mathrm{H}_{2} \mathrm{O}$ is stronger than $\mathrm{Mg}(\mathrm{OH})_{2}$ [24], opening up the possibility of using it as a suitable support for oxidation reactions of alcohols. Therefore, data compilation suggests that materials based on strontium supports are not scrutinized in literature for gold-based catalysts.

Herein, we propose the effect of $\mathrm{Sr}(\mathrm{OH})_{2}$ supports on the oxidation of benzyl alcohol as a model reaction. The supports were prepared with simple methodologies, and Au NPs were synthesized using a PVA-stabilized approach with $\mathrm{NaBH}_{4}$ reduction. The reactions were carried out in solvent-free conditions without any addition of extra base at the beginning to demonstrate the catalyst basicity and pertinence to the reaction. Then, reactions with sub-stoichiometry $\mathrm{K}_{2} \mathrm{CO}_{3}$ were performed to improve the catalyst reusability [25]. The oxidation of benzyl alcohol by molecular oxygen in low pressure ( 2 bar) and in $2.5 \mathrm{~h}$ revealed that the catalysts have a very good activity and high selectivity, with a remarkable performance achieved with the calcined support. Studies of XPS, TEM, and recyclability were important to correlate the activity to the material obtained.

\section{Results and Discussion}

Gold NPs were prepared using the well-known sol-stabilization method with PVA [26]. This method was chosen due to its reproducibility, robustness, and good sol stability, although PVA may have some effect on the activity of gold catalysts [27]. Strontium-based supports were used in an attempt to enhance the basicity of the catalysts to further boost its properties. Since differences between oxide and hydroxide have been demonstrated to affect the activity of gold catalysts in magnesium-based supports [12], we decided to explore the influence of strontium-base materials on oxidation of benzyl alcohol, since studies suggested its superior activity when compared to $\mathrm{Mg}(\mathrm{OH})_{2}$ [24], a very common material used for gold catalysts synthesis. Previous studies express by titration the strength of basic sites on a scale given by the $\mathrm{H}_{-}$function, defined by the equation:

$$
\mathrm{H}_{-}=\mathrm{pK}_{\mathrm{a}}+\log \frac{\left[\mathrm{B}^{-}\right]}{[\mathrm{BH}]}
$$

in which the $\mathrm{pK}_{\mathrm{a}}$ value is for a chosen Hammett indicator and $[\mathrm{BH}]$ and $\left[\mathrm{B}^{-}\right]$are the concentration of the indicator and its conjugated base, respectively. $\mathrm{MgO}$ has basic sites estimated in $\mathrm{H}_{-}=26$, and SrO presents $\mathrm{H}_{-}<18$. However, $\mathrm{Sr}(\mathrm{OH})_{2}$ calcined at $1123 \mathrm{~K}$ presents basic sites with $\mathrm{H}_{-} \leq 26.5$ [9]. Based on such antecedent findings, we decided to explore strontium-based materials. According to the experimental section, the material synthesized with the calcined support was assigned as $\mathrm{Au} /$ calc-Sr sup and the one without calcination was assigned as $\mathrm{Au} / \mathrm{Sr}_{\text {sup }}$. For both materials, the base strength measured by the Hammett indicator method was found to be $13.7<\mathrm{H}_{-}<18.4$. Such catalysts are considered to be strongly basic, and any difference from the literature may be due to the synthesis process that the supports underwent for the Au NPs impregnation and washing. 
To shed some light on the chemical state of the gold species immobilized, since the NPs syntheses were performed in different solvents, $\mathrm{Au} / \mathrm{Sr}_{\text {sup }}$ and $\mathrm{Au} / \mathrm{calc}_{\mathrm{C}} \mathrm{Sr}_{\text {sup }}$ samples were analyzed by XPS (Company, City, Country). As portrayed in Figure 1, both catalysts presented the characteristic $\mathrm{Au}$ $4 \mathrm{f}_{5 / 2}$ and $\mathrm{Au} 4 \mathrm{f}_{7 / 5}$ XPS bands. The two XPS components observed for the samples are indicated in Figure $1 \mathrm{a}, \mathrm{b}$ and are basically the same $\left(83.4 \mathrm{eV}\right.$ and $87.2 \mathrm{eV}$ for $\mathrm{Au} /$ calc-Sr $\mathrm{S}_{\text {sup }}$ and $83.5 \mathrm{eV}$ and $87.3 \mathrm{eV}$ for $\left.\mathrm{Au} / \mathrm{Sr}_{\text {sup }}\right)$. The bands are assigned to the spin-orbit components of the Au- $4 \mathrm{f}$ level, which could be attributed to metallic gold species [28]. The acetone-stabilized Au NPs were prepared in an attempt to maintain the oxide phase of the calcined support (calc-Sr sup). The XPS data for this $\mathrm{Au}$ NPs preparation approach presented no significant difference between the water-stabilized gold NPs. Therefore, Rietveld refinement was performed to determine the main phases obtained after the catalyst synthesis via Au NPs immobilization for both catalysts (Figure 2).
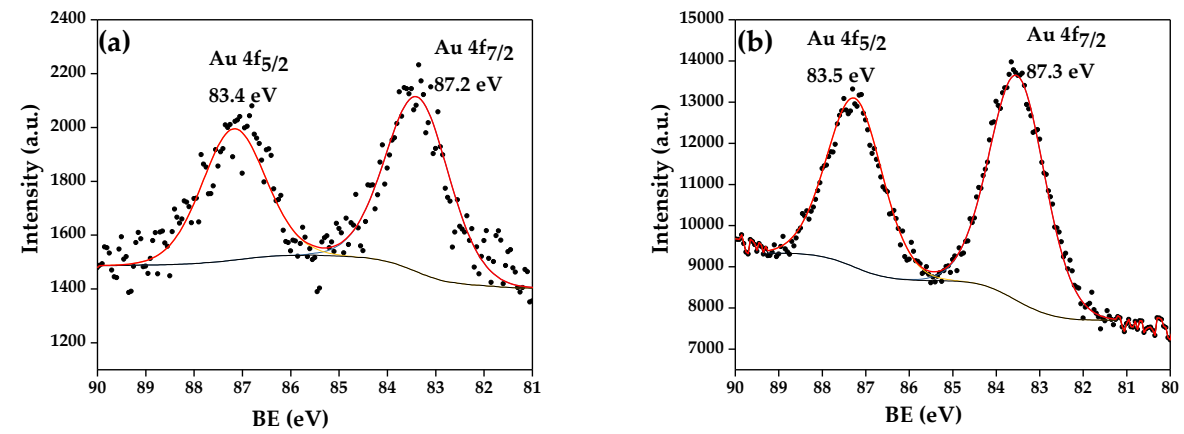

Figure 1. XPs spectra of $\mathrm{Au} 4 \mathrm{f}$ level of (a) Au/calc-Sr sup and (b) $\mathrm{Au} / \mathrm{Sr}_{\text {sup }}$ catalysts. The red line represents the fitted spectrum and the black one is the background.
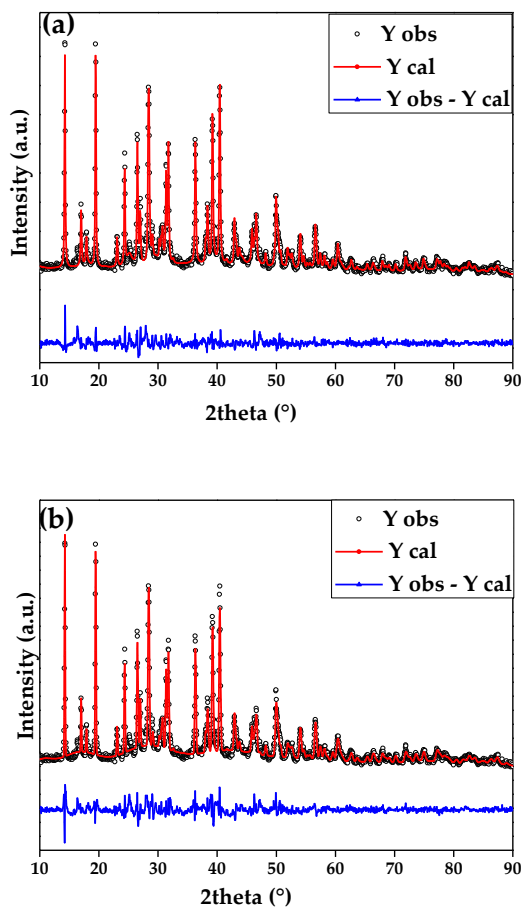

Figure 2. Rietveld refinement plot for (a) Au/calc-Sr $r_{\text {sup }}$ and (b) Au/calc-Sr $r_{\text {sup }}$ catalysts, showing the observed, calculated, and difference pattern.

The diffraction pattern used in the refinement were indexed to SrO (ICSD 20960), $\mathrm{SrCO}_{3}$ (ICSD 207393), $\mathrm{Sr}(\mathrm{OH})_{2} \cdot \mathrm{H}_{2} \mathrm{O}$ (ICSD 60661), and $\mathrm{Sr}(\mathrm{OH})_{2}$ (ICSD 15167) crystalline phases. The Rietveld refinement results for the $\mathrm{Au} / \mathrm{calc}_{\mathrm{C}} \mathrm{Sr}_{\text {sup }}$ catalyst indicated that the majority phases are comprised 
of $\mathrm{Sr}(\mathrm{OH})_{2} \cdot \mathrm{H}_{2} \mathrm{O}(25.5 \%)$ and $\mathrm{Sr}(\mathrm{OH})_{2}(59.2 \%) ; 15.3 \%$ remained as $\mathrm{SrCO}_{3}$. For the $\mathrm{Au} / \mathrm{Sr}_{\text {sup }}$ catalyst, the phase composition was $24.5 \%$ for $\mathrm{Sr}(\mathrm{OH})_{2}$ and $75.5 \%$ for $\mathrm{Sr}(\mathrm{OH})_{2} \cdot \mathrm{H}_{2} \mathrm{O}$. The results specifically show that the acetone-stabilized Au NPs were not able to maintain the SrO phase. Hence, strontium oxide was not considered in the studies performed here due to its easy transformation to $\operatorname{Sr}(\mathrm{OH})_{2}$ via interaction with water, as attested by the refinements carried out.

The low concentration and small size of the Au NPs in both catalysts hampered the observation of Au diffraction peaks on the materials; the metal NPs characteristics were analyzed by TEM, as shown in Figure 3.
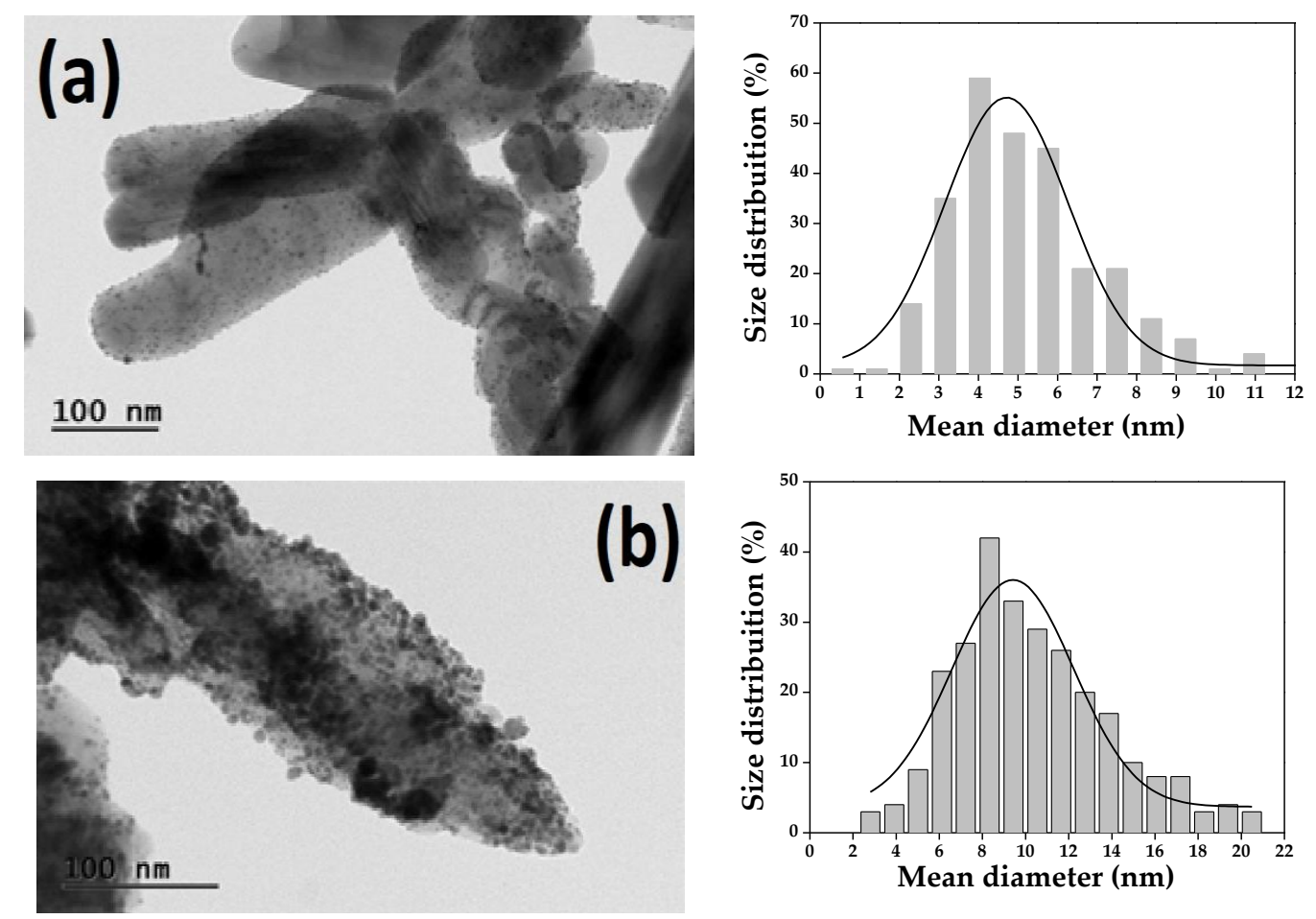

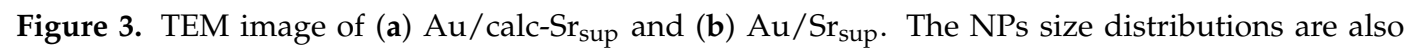
provided for both materials.

TEM image for Au/calc-Sr sup catalyst (Figure 3a) revealed well-dispersed Au NPs with a mean diameter of $5.2 \pm 1.9 \mathrm{~nm}$. For $\mathrm{Au} / \mathrm{Sr}_{\text {sup }}$ catalyst, the size distribution was $10.3 \pm 3.6 \mathrm{~nm}$ (Figure $3 \mathrm{~b}$ ), with a poor dispersion. One may notice that the NPs obtained for the catalyst prepared in water presented a narrow size distribution, although they were slightly broader when compared to NPs synthesized in acetone, as occasionally much larger particles are observed in the sample. This leads to larger surface-average size for the catalyst and may be associated with the solvent used for the synthesis.

The catalytic activity of the $\mathrm{Au} / \mathrm{calc}-\mathrm{Sr}_{\text {sup }}$ and $\mathrm{Au} / \mathrm{Sr}_{\text {sup }}$ catalysts was tested in the solvent-free oxidation of benzyl alcohol (Figure 4) under the standard reaction conditions outlined in the experimental Section, without co-catalysts or additives. The metal uptake for Au/calc-Sr sup catalyst was $1.5 \mathrm{wt} \%$ and for $\mathrm{Au} / \mathrm{Sr}_{\text {sup }}$ was $2.0 \mathrm{wt} \%$, according to FAAS data. To establish if there was any conversion of the benzyl alcohol in the absence of the catalysts, a blank reaction was performed under the same reaction conditions. Without catalyst in the reaction medium, the conversion of the reagent was $0.1 \%$, which is within experimental error. Two other separate blank tests were carried out with the as-synthesized calcined and not-calcined supports. For both, the conversions were negligible as well. The oxidation of benzyl alcohol was carried out with $\mathrm{Au} / \mathrm{calc}-\mathrm{Sr}_{\text {sup }}$ and $\mathrm{Au} / \mathrm{Sr}_{\text {sup }}$ without base addition at $100{ }^{\circ} \mathrm{C}, 120^{\circ} \mathrm{C}$, and $140{ }^{\circ} \mathrm{C}$. The results are displayed in Table 1 . The influence of the temperature reaction for both catalysts did not lead to any significant conversion increasing in a 
range of $100-140{ }^{\circ} \mathrm{C}$, although some influence on the selectivity was observed. For the Au/calc-Sr $r_{\text {sup }}$ catalyst, very remarkable conversions were obtained in just $2.5 \mathrm{~h}$ of reaction and 2 bar of $\mathrm{O}_{2}$, taking into consideration that no base was used (entries 1-3). Yields of $54.6 \%, 62.7 \%$, and $67.4 \%$ were achieved at $100{ }^{\circ} \mathrm{C}, 120^{\circ} \mathrm{C}$, and $140{ }^{\circ} \mathrm{C}$, respectively. Increasing the temperature, a slight conversion augmentation was observed, and the selectivity to benzaldehyde was also improved. For the $\mathrm{Au} / \mathrm{Sr}_{\text {sup }}$ catalyst, the temperature effect on the conversion was more noticeable, with benzoic acid enhancement (entries 4-6). Choudhary and co-workers presented a gold-magnesium catalyst for the solvent-free oxidation of benzyl alcohol. In $5 \mathrm{~h}$, under $1.5 \mathrm{bar}, 130{ }^{\circ} \mathrm{C}$, and substrate/metal molar ratio of 725 , the authors obtained $51 \%$ of conversion. The proposed $\mathrm{Au} / \mathrm{Sr}_{\text {sup }}$ catalyst presented in $2.5 \mathrm{~h}, 2 \mathrm{bar}$, $140{ }^{\circ} \mathrm{C}$, and substrate/metal molar ratio of 2180 a conversion of $67.4 \%$, which shows the applicability of the material [29]. Other examples using $\mathrm{MgO}$ and $\mathrm{Mg}(\mathrm{OH})_{2}$ are also available in the literature; however, with the solvent addition [11,12]. Comparisons with such studies and the Au/calc-Sr sup catalyst present the superior activity of the proposed system. Albeit the temperature to some extent influenced the selectivity, the conversions are not modified, with $100{ }^{\circ} \mathrm{C}$ being the temperature that was set for other experiments that were further performed. Our studies were based on the substrate/metal ratios calculated by bearing in mind the total amount of gold, which was determined by FAAS. Such information is considered correct by many researchers, as presented before; however, one may notice that the number of surface atoms is much lower than that obtained for bulky NPs. Composition results from XPS analysis (Supplementary Information, Figures S1 and S2) of the Au/calc-Sr sup catalyst showed the presence of $\mathrm{O}, \mathrm{Sr}, \mathrm{Au}, \mathrm{Cl}$, and $\mathrm{Na}$. The $\mathrm{Au}$ atomic concentration was $0.13 \%$. When removing the contributions from $\mathrm{Na}$ and $\mathrm{Cl}$, the renormalized data presents at $\%$ for $\mathrm{Au}$ of 0.22 . Such data may be relevant to evaluate the performance per active site.

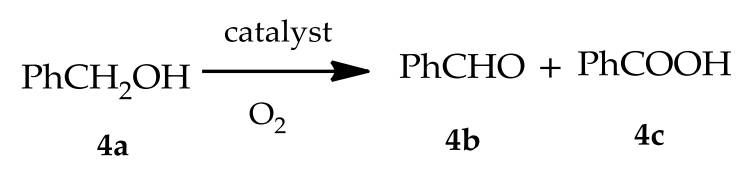

Figure 4. Oxidation of benzyl alcohol (4a) into benzaldehyde (4b) and benzoic acid (4c).

Table 1. Oxidation of benzyl alcohol (4a) with molecular oxygen using $\mathrm{Au} / \mathrm{calc}-\mathrm{Sr}_{\text {sup }}$ and $\mathrm{Au} / \mathrm{Sr}_{\text {sup }}$ catalysts ${ }^{1}$.

\begin{tabular}{|c|c|c|c|c|c|}
\hline \multirow{2}{*}{ Entry } & \multirow{2}{*}{ Temperature $\left({ }^{\circ} \mathrm{C}\right)$} & \multirow{2}{*}{ Catalyst } & \multirow{2}{*}{ Conversion (\%) } & \multicolumn{2}{|c|}{ Selectivity (\%) } \\
\hline & & & & $4 b$ & $4 c$ \\
\hline 1 & 100 & $\mathrm{Au} / \mathrm{calc}-\mathrm{Sr}_{\text {sup }}$ & 54.6 & 59.5 & 40.5 \\
\hline 2 & 120 & $\mathrm{Au} / \mathrm{calc}_{\mathrm{l}}-\mathrm{Sr}_{\text {sup }}$ & 62.7 & 60.6 & 39.4 \\
\hline 3 & 140 & $\mathrm{Au} / \mathrm{calc}_{\mathrm{l}}-\mathrm{Sr}_{\text {sup }}$ & 67.4 & 78.7 & 21.3 \\
\hline 4 & 100 & $\mathrm{Au} / \mathrm{Sr}_{\text {sup }}$ & 7.3 & 80.8 & 19.2 \\
\hline 5 & 120 & $\mathrm{Au} / \mathrm{Sr}_{\text {sup }}$ & 16.2 & 73.1 & 26.9 \\
\hline 6 & 140 & $\mathrm{Au} / \mathrm{Sr}_{\text {sup }}$ & 24.74 & 68.2 & 31.8 \\
\hline
\end{tabular}

The NPs size differences may explain the lower activity in the $\mathrm{Au} / \mathrm{Sr}_{\text {sup }}$, whereas the sample presents larger NPs $(10.3 \pm 3.6 \mathrm{~nm})$; however, that is not the only aspect to be considered. Significant differences were found concerning the dispersion and aggregation of the nanoparticles, which leads to a decrease in catalytic activity of the $\mathrm{Au} / \mathrm{Sr}_{\text {sup }}$ catalyst by lowering its surface area. As the syntheses of the supports were found to be essentially strontium hydroxide, the size and dispersibility differences of the NPs are considered to be responsible for the effects observed. However, the support-NPs interactions may not be disregarded, as well as the support synthesis processes. Lopez-Sanchez et al. have concluded PVA-stabilized gold NPs may have its activity affected by the stabilizer for CO oxidation reactions. They proposed an efficient water extraction method that is able to clean the NPs surface, maintaining their size and morphology [30]. The Au/calc-Sr sup catalyst is very active considering that no base was added to the reaction medium; therefore, we performed an extraction with acetone, and it was applied to this material with some modifications. The catalyst was refluxed 
for $12 \mathrm{~h}$ in a Soxhlet apparatus and washed with acetone and dried. After the procedure, the catalyst was used under the same reaction conditions for benzyl alcohol oxidation. No significant activity improvement was observed, although a slight benzaldehyde selectivity enhancement was detected. Nevertheless, the PVA has no effect drawbacks on the system proposed.

One of our main interests was to determine the catalytic activity and reusability of the proposed system. For this proposal, the $\mathrm{Au} / \mathrm{calc}^{-\mathrm{Sr}_{\text {sup }}}$ was the chosen one, since its activity is significantly higher than that observed for $\mathrm{Au} / \mathrm{Sr}_{\text {sup }}$ catalyst. The stability of the catalyst was evaluated by recycling experiments (Figure 5) without base addition and with $\mathrm{K}_{2} \mathrm{CO}_{3}$ as an additional base. The base addition was decided based on previous studies [25]. In the recycling experiments without base addition, the catalyst was washed there times with acetone; nevertheless, the experiments carried out with $\mathrm{K}_{2} \mathrm{CO}_{3}$ were washed with water to remove the base from the previous cycle and, then, three times with acetone. Figure 5 a clearly shows that the $\mathrm{Au} / \mathrm{calc}^{-} \mathrm{Sr}_{\text {sup }}$ catalyst, without extra-base addition, presents considerable deactivation in successive runs. The same catalyst, in presence of the base, presented a similar conversion for the first run; however, it remained stable with similar conversion and selectivity in the recycling tests. Some of us have studied base-free promoted benzyl alcohol oxidation with comparable results [18]. It is quite unexpected that the catalyst with additional base presents similar performance as the observed for the base-free counterpart. FAAS analyses of the spent catalyst after the fifth run showed no leaching in the catalyst with $\mathrm{K}_{2} \mathrm{CO}_{3}$, but ca. of $70 \%$ of $\mathrm{Au}$ leaching was detected in the material used without the additional base. These results suggest that the synthesized catalyst is active without the base; however, it loses its activity due to the pronounced leaching. The base addition works on the catalyst stabilization. The catalyst used in presence of base did not show any sign of deactivation and may be used in further cycles. Data obtained open up the possibility of application of this catalyst with other $\mathrm{pH}$ environments in water conditions [25], improving the selectivity.
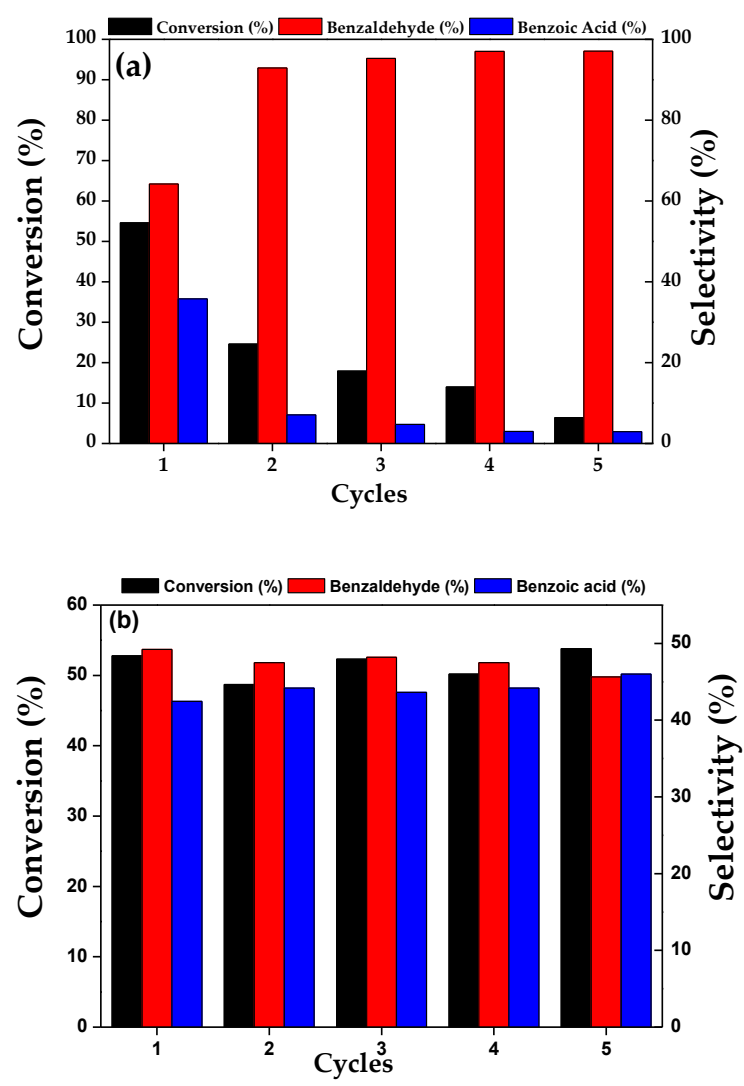

Figure 5. Recycling tests for the Au/calc-Sr $r_{\text {sup }}$ catalyst in benzyl alcohol oxidation under (a) base-free conditions and (b) $\mathrm{K}_{2} \mathrm{CO}_{3}$ extra-base addition. 


\section{Materials and Methods}

\subsection{Materials}

All chemicals used in the experiments were of analytical grade and used without further purification.

\subsection{Catalytic Supports Preparation}

The supports were prepared according to literature with modifications [30]. For one of them, $50 \mathrm{~mL}$ of strontium nitrate $\left(1 \mathrm{~mol} \mathrm{~L}^{-1}\right)$ and $50 \mathrm{~mL}$ of sodium hydroxide $\left(2 \mathrm{~mol} \mathrm{~L}^{-1}\right)$ were mixed and constantly stirred for $1 \mathrm{~h}$. The mixture was centrifuged for $5 \mathrm{~min}$ at $2400 \mathrm{rpm}$ and a white precipitate was obtained by pouring the supernatant off. The solid was calcined in a muffle furnace for $4 \mathrm{~h}$ at $1100{ }^{\circ} \mathrm{C}$ and labelled as cal-Sr sup. The second support was prepared by a similar procedure, without calcination. After the precipitate obtaining, the solid was washed with distilled water ( 3 times, $20 \mathrm{~mL}$ each) and acetone (once, $20 \mathrm{~mL}$ ) and dried in an oven at $70{ }^{\circ} \mathrm{C}$. This support was labelled just as $\mathrm{Sr}_{\text {sup }}$.

\subsection{Au NPs Synthesis}

$\mathrm{Au}$ NPs were prepared by a method described elsewhere with modifications [26]. The Au NPs were prepared in water or in acetone, depending on the support chosen for the impregnation; the selected procedure will be highlighted when necessary. In a typical procedure, $1.80 \mathrm{~mL}$ of a freshly prepared $2.0 \mathrm{wt} \%$ aqueous solution of polyvinyl alcohol (PVA 80\%, $36 \mathrm{mg}$ ) was added to a solution of $\mathrm{HAuCl}_{4}(172.5 \mathrm{mg}, 300 \mathrm{~mL})$, in water or acetone, under magnetic stirring (800 rpm). After this step, an ice-cold freshly prepared $\mathrm{NaBH}_{4}$ aqueous solution $\left(7.65 \mathrm{~mL}, 0.1 \mathrm{~mol} \mathrm{~L}{ }^{-1}\right)$ was added drop-by-drop to reduce the metal, under the same magnetic stirring. The solution turned immediately to a dark purple color and was further stirred for 30 additional minutes.

\subsection{Synthesis of the Catalysts}

After the sol synthesis, the colloids were immobilized on the supports. The colloidal solutions were simply added to the solids; however, the NPs prepared in water were used to the $\mathrm{Sr}_{\text {sup, }}$ while

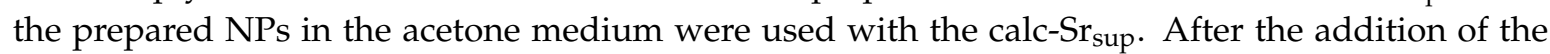
pre-formed NPs to the supports, the mixture was vigorously stirred for $2 \mathrm{~h}$ at room temperature. The amount of NPs was considered to provide $2.0 \mathrm{wt} \%$ of metal on the support. After this step, the slurry was centrifuged and further washed with acetone ( 3 times, $20 \mathrm{~mL}$ each) and dried in an oven at $70{ }^{\circ} \mathrm{C}$ for $1 \mathrm{~h}$. At the ending of the procedure, the catalysts were stored in amber bottles and placed in the desiccator. The catalysts were named as follows: $\mathrm{Au} / \mathrm{Sr}_{\text {sup }}$ ( $\mathrm{Au}$ NPs stabilized in water) and $\mathrm{Au} / \mathrm{calc}_{\mathrm{S}} \mathrm{Sr}_{\text {sup }}$ (Au NPs stabilized in acetone). The metal content in the catalysts was determined by FAAS.

\subsection{Characterization of Catalysts}

Transmission electron microscopy (TEM) images were obtained using JEM-2100 microscope (operating at 110 kV, JEOL, Peabody, MA, USA). Samples were prepared by drop casting an isopropanol suspension of the samples over a carbon-coated copper grid, followed by drying under room temperature. Furnace Atomic Absorption Spectroscopy (FAAS) was performed using AA-6300 spectrophotometer (Shimadzu, Kyoto, Japan). The X-ray diffractograms (XRD) were obtained using D8 Advance equipment (Bruker, Billerica, MA, USA) with monochromatic Cu K $\alpha$ radiation $(\lambda=1.54056 \AA)$ and a graphite monochromator. The voltage of the copper emission tube was $40 \mathrm{kV}$ and the filament current was $40 \mathrm{~mA}$, at a $2 \theta$ range from $10^{\circ}$ to $90^{\circ}$ with a $0.02^{\circ}$ step size and measuring the time of $5 \mathrm{~s}$ per step. The X-ray photoemission spectra were obtained with a ESCA + spectrometer system equipped with an EA 125 hemispherical analyzer and a XM 1000 monochromated X-ray source (Scientia Omicron, Uppsala, Sweden) in Al $\mathrm{K} \alpha(1486.7 \mathrm{eV})$. The X-ray source was used with a power of $280 \mathrm{~W}$, as the 
spectrometer worked in a constant pass energy mode of $50 \mathrm{eV}$. The phase composition identifications were performed by Rietveld refinement using GSAS EXPGUI 2012 software [26].

\subsection{Catalytic Reactions}

The oxidation reactions were carried out using a $100 \mathrm{~mL}$ Fischer-Porter glass reactor (EMPER, Porto Alegre, Brazil) in solvent-free conditions. The reactor was loaded with the catalysts $(4.4 \mu \mathrm{mol}$ de $\mathrm{Au}$ ), benzyl alcohol $(9.6 \mathrm{mmol})$, and 2 bar of $\mathrm{O}_{2}$. Using a ceramic heating plate with temperature digital controller, the reactions were performed at $100{ }^{\circ} \mathrm{C}$ (except when specified) for $2.5 \mathrm{~h}$ under magnetic stirring. The products were separated from the catalyst by centrifugation. Then, $5 \mu \mathrm{L}$ were collected and added to $1 \mathrm{~mL}$ do $\mathrm{CH}_{2} \mathrm{Cl}_{2}$ and $1 \mu \mathrm{L}$ of the solution was injected into a CG-2010 Plus chromatograph (Shimadzu, Kyoto, Japan) equipped with a flame ionization detector and a Carbowax capillary column. For the recycling tests, two processes were performed: for base-free reactions, the catalyst was washed once with acetone; for the reactions with $\mathrm{K}_{2} \mathrm{CO}_{3}$, the catalyst was washed 3 times with water and once with acetone.

\subsection{NPs Surface Cleaning}

The NPs surface cleaning was performed based on Lopez-Sanchez et al., with modifications [31]. About $1 \mathrm{~g}$ of catalyst was place in a Soxhlet apparatus with $50 \mathrm{~mL}$ of acetone; the system was refluxed in a heating bath set to $90^{\circ} \mathrm{C}$. The process took $12 \mathrm{~h}$. The mixture was centrifuged, washed 3 times with acetone, and dried overnight at $70{ }^{\circ} \mathrm{C}$.

\subsection{Basic Strengh of the Catalysts}

The basic strength of the catalysts (H_) was determined by using various Hammett indicators [32]. About $100 \mathrm{mg}$ of the materials were shaken with $5 \mathrm{~mL}$ of methanolic solutions of the indicators. The solutions were left to stand for $2 \mathrm{~h}$ until no color changes were observed. The basic strength is reported as being stronger than the weakest indicator, when a color change is observed, and weaker than the strongest indicator, when there is no color change. The Hammett indicators used were: neutral red $\left(H_{-}=6.8\right)$, bromothymol blue $\left(H_{-}=7.2\right)$, phenolphthalein $\left(H_{-}=9.3\right)$, 2,4-dinitroaniline $\left(H_{-}=15.0\right)$, and 4-nitroaniline $\left(\mathrm{H}_{-}=18.4\right)$.

\section{Conclusions}

PVA-stabilized gold NPs impregnated on strontium-based supports were amply considered on the studies presented herein. Seemingly, the potential of these materials is not fully explored in the literature. By using Rietveld refinements, we proposed the phase composition of the supports used in our studies, which is highly important to granting the correct characterization of the materials synthesized. The Au/calc-Sr sup catalyst, prepared by support calcination prior to the Au NPs immobilization, presented the best performance. XPS analyses were used and attested metallic gold NPs obtaining, no matter which solvent (water or acetone) was used for the NPs stabilization. Also, such analyses were important, in order to specify the Au atomic concentration that was available for the catalysis. Catalytic tests evidenced that the calcination step was important in the performance, although the NPs size and dispersity may have a decisive effect on the catalytic activity. Correlations between $\mathrm{Au} / \mathrm{calc}-\mathrm{Sr}_{\text {sup }}$ and $\mathrm{Au} / \mathrm{Sr}_{\text {sup }}$ showed that the former presented a narrower size distribution after immobilization, as well as better distribution on the support. The $\mathrm{Au} / \mathrm{calc}-\mathrm{Sr}_{\text {sup }}$ catalyst was efficiently used for benzyl alcohol oxidation without base addition. Titration measurements confirmed the intrinsic basicity of the support, a feature that may explain the activity of the catalysts without extra base. However, sub-stoichiometric $\mathrm{K}_{2} \mathrm{CO}_{3}$ adding was essential for the recyclability of the material. Although the activities are similar with or without the extra base, the stability of the catalyst was only observed when $\mathrm{K}_{2} \mathrm{CO}_{3}$ was applied in the oxidation system. 
Supplementary Materials: The following are available online at http:/ /www.mdpi.com/xxx/s1, Figure S1: XPS pattern of the $\mathrm{Au} / \mathrm{Sr}_{\text {sup }}$ catalyst considering the presence of $\mathrm{O}, \mathrm{Sr}, \mathrm{Au}, \mathrm{Cl}$ and $\mathrm{Na}$ for the at.\% calculation, Figure S2: XPS pattern of the $\mathrm{Au} / \mathrm{Sr}_{\text {sup }}$ catalyst disregarding the presence of $\mathrm{Cl}$ and $\mathrm{Na}$ for the at.\% calculation.

Acknowledgments: The authors acknowledge financial support from FAPEPI and CNPq and the technical support of Center for Strategic Technology of the Northeast (CETENE-PE). Thanks to CCMC/CDMF (FAPESP No. 2013/07296-2, Brazil) for the XPS measurements. The authors also acknowledge Renato V. Gonçalves for the support with XPS measurements and analyzes and Nadiah Mohamad Noh for the English corrections.

Author Contributions: Edmilson M. de Moura and Marco Aurélio S. Garcia conceived the study; Karla Patrícia R. Castro, Wiury C. de Abreu, and Samuel Anderson A. de Sousa performed the experiments; Carla Verônica R. de Moura contributed with reagents/materials; Jean Cláudio S. Costa contributed with TEM analyses. All the authors contributed to the writing of the manuscript.

Conflicts of Interest: The authors declare no conflict of interest.

\section{References}

1. Prati, L.; Rossi, M. Gold on Carbon as a New Catalyst for Selective Liquid Phase Oxidation of Diols. J. Catal. 1998, 176, 552-560. [CrossRef]

2. Prati, L.; Martra, G. New gold catalysts for liquid phase oxidation. Gold Bull. 1999, 32, 96-101. [CrossRef]

3. Porta, F.; Prati, L.; Rossi, M.; Coluccia, S.; Martra, G. Metal sols as a useful tool for heterogeneous gold catalyst preparation: Reinvestigation of a liquid phase oxidation. Catal. Today 2000, 61, 165-172. [CrossRef]

4. Carrettin, S.; McMorn, P.; Johnston, P.; Griffin, K.; Kiely, C.J.; Hutchings, G.J. Oxidation of glycerol using supported Pt, Pd and Au catalysts. Phys. Chem. Chem. Phys. 2003, 5, 1329-1336. [CrossRef]

5. Silva, T.A.G.; Landers, R.; Rossi, L.M. Magnetically recoverable AuPd nanoparticles prepared by a coordination capture method as a reusable catalyst for green oxidation of benzyl alcohol. Catal. Sci. Technol. 2013, 3, 2993-2999. [CrossRef]

6. Enache, D.I.; Edwards, J.K.; Landon, P.; Solsona-Espriu, B.; Carley, A.F.; Herzing, A.A.; Watanabe, M.; Kiely, C.J.; Knight, D.W.; Hutchings, G.J. Solvent-Free Oxidation of Primary Alcohols to Aldehydes Using $\mathrm{Au}-\mathrm{Pd} / \mathrm{TiO}_{2}$ Catalysts. Science 2006, 311, 362-365. [CrossRef] [PubMed]

7. Brett, G.L.; He, Q.; Hammond, C.; Miedziak, P.J.; Dimitratos, N.; Sankar, M.; Herzing, A.A.; Conte, M.; Lopez-Sanchez, J.A.; Kiely, C.J.; et al. Selective Oxidation of Glycerol by Highly Active Bimetallic Catalysts at Ambient Temperature under Base-Free Conditions. Angew. Chem. Int. Ed. 2011, 50, 10136-10139. [CrossRef] [PubMed]

8. Han, Y.; Ferrando, R.; Li, Z.Y. Atomic Details of Interfacial Interaction in Gold Nanoparticles Supported on $\mathrm{MgO}(001)$. J. Phys. Chem. Lett. 2014, 5, 131-137. [CrossRef] [PubMed]

9. Corma, A.; Iborra, S. Optimization of Alkaline Earth Metal Oxide and Hydroxide Catalysts for Base-Catalyzed Reactions. Adv. Catal. 2006, 49, 239-302. [CrossRef]

10. Choudhary, V.R.; Dumbre, D.K. Solvent-free selective oxidation of primary alcohols-to-aldehydes and aldehydes-to-carboxylic acids by molecular oxygen over MgO-supported nano-gold catalyst. Catal. Commun. 2011, 13, 82-86. [CrossRef]

11. Costa, V.V.; Estrada, M.; Demidova, Y.; Prosvirin, I.; Kriventsov, V.; Cotta, R.F.; Fuentes, S.; Simakov, A.; Gusevskaya, E.V. Gold nanoparticles supported on magnesium oxide as catalysts for the aerobic oxidation of alcohols under alkali-free conditions. J. Catal. 2012, 292, 148-156. [CrossRef]

12. Estrada, M.; Costa, V.V.; Beloshapkin, S.; Fuentes, S.; Stoyanov, E.; Gusevskaya, E.V.; Simakov, A. Aerobic oxidation of benzyl alcohol in methanol solutions over Au nanoparticles: $\mathrm{Mg}(\mathrm{OH})_{2}$ vs $\mathrm{MgO}$ as the support. Appl. Catal. A Gen. 2014, 473, 96-103. [CrossRef]

13. Conte, M.; Liu, X.; Murphy, D.M.; Whiston, K.; Hutchings, G.J. Cyclohexane oxidation using Au/MgO: An investigation of the reaction mechanism. Phys. Chem. Chem. Phys. 2012, 14, 16279-16285. [CrossRef] [PubMed]

14. Wang, Z.; Xu, C.; Wang, H. A Facile Preparation of Highly Active Au/MgO Catalysts for Aerobic Oxidation of Benzyl Alcohol. Catal. Lett. 2014, 144, 1919-1929. [CrossRef]

15. Boronat, M.; Corma, A.; Illas, F.; Radilla, J.; Ródenas, T.; Sabater, M.J. Mechanism of selective alcohol oxidation to aldehydes on gold catalysts: Influence of surface roughness on reactivity. J. Catal. 2011, 278, 50-58. [CrossRef] 
16. Villa, A.; Veith, G.M.; Prati, L. Selective Oxidation of Glycerol under Acidic Conditions Using Gold Catalysts. Angew. Chem. 2010, 122, 4601-4604. [CrossRef]

17. Klitgaard, S.K.; DeLa Riva, A.T.; Helveg, S.; Werchmeister, R.M.; Christensen, C.H. Aerobic Oxidation of Alcohols over Gold Catalysts: Role of Acid and Base. Catal. Lett. 2008, 126, 213-217. [CrossRef]

18. De Moura, E.M.; Garcia, M.A.S.; Goncalves, R.V.; Kiyohara, P.K.; Jardim, R.F.; Rossi, L.M. Gold nanoparticles supported on magnesium ferrite and magnesium oxide for the selective oxidation of benzyl alcohol. RSC Adv. 2015, 5, 15035-15041. [CrossRef]

19. Brown, M.A.; Fujimori, Y.; Ringleb, F.; Shao, X.; Stavale, F.; Nilius, N.; Sterrer, M.; Freund, H.-J. Oxidation of Au by Surface OH: Nucleation and Electronic Structure of Gold on Hydroxylated MgO(001). J. Am. Chem. Soc. 2011, 133, 10668-10676. [CrossRef] [PubMed]

20. Choudhary, V.R.; Dumbre, D.K. Supported Nano-Gold Catalysts for Epoxidation of Styrene and Oxidation of Benzyl Alcohol to Benzaldehyde. Top. Catal. 2009, 52, 1677-1687. [CrossRef]

21. Takei, T.; Iguchi, N.; Haruta, M. Support effect in the gas phase oxidation of ethanol over nanoparticulate gold catalysts. New J. Chem. 2011, 35, 2227-2233. [CrossRef]

22. Zhang, G.; Hattori, H.; Tanabe, K. Aldol Addition of Acetone, Catalyzed by Solid Base Catalysts: Magnesium Oxide, Calcium Oxide, Strontium Oxide, Barium Oxide, Lanthanum (III) Oxide and Zirconium Oxide. Appl. Catal. 1988, 36, 189-197. [CrossRef]

23. Kabashima, H.; Tsuji, H.; Hattori, H. Double bond isomerization of 5-vinylbicyclo[2.2.1]hept-2-ene to 5-ethylidenebicyclo[2.2.1]hept-2-ene over alkaline earth oxides. React. Kinet. Catal. Lett. 1996, 58, $255-259$. [CrossRef]

24. Kabashima, H.; Katou, T.; Hattori, H. Conjugate addition of methanol to 3-buten-2-one over solid base catalysts. Appl. Catal. A Gen. 2001, 214, 121-124. [CrossRef]

25. Ferraz, C.P.; Garcia, M.A.S.; Teixeira-Neto, E.; Rossi, L.M. Oxidation of benzyl alcohol catalyzed by gold nanoparticles under alkaline conditions: Weak vs. Strong bases. RSC Adv. 2016, 6, 25279-25285. [CrossRef]

26. Meenakshisundaram, S.; Nowicka, E.; Miedziak, P.J.; Brett, G.L.; Jenkins, R.L.; Dimitratos, N.; Taylor, S.H.; Knight, D.W.; Bethell, D.; Hutchings, G.J. Oxidation of alcohols using supported gold and gold-palladium nanoparticles. Faraday Discuss. 2010, 145, 341-356. [CrossRef]

27. Villa, A.; Wang, D.; Veith, G.M.; Vindigni, F.; Prati, L. Sol immobilization technique: A delicate balance between activity, selectivity and stability of gold catalysts. Catal. Sci. Technol. 2013, 3, 3036-3041. [CrossRef]

28. Love, C.S.; Chechik, V.; Smith, D.K.; Wilson, K.; Ashworth, I.; Brennan, C. Synthesis of gold nanoparticles within a supramolecular gel-phase network. Chem. Commun. 2005, 1971-1973. [CrossRef] [PubMed]

29. Choudhary, V.R.; Dhar, A.; Jana, P.; Jha, R.; Uphade, B.S. A green process for chlorine benzaldehyde from solvent-free oxidation of benzyl alcohol with molecular oxygen over a supported nano-size gold catalyst. Green Chem. 2005, 7, 768. [CrossRef]

30. Song, L.; Li, Y.; He, P.; Zhang, S.; Wu, X.; Fang, S.; Shan, J.; Sun, D. Synthesis and sonocatalytic property of rod-shape $\mathrm{Sr}(\mathrm{OH})_{2} \cdot 8 \mathrm{H}_{2} \mathrm{O}$. Ultrason. Sonochem. 2014, 21, 1318-1324. [CrossRef] [PubMed]

31. Lopez-Sanchez, J.A.; Dimitratos, N.; Hammond, C.; Brett, G.L.; Kesavan, L.; White, S.; Miedziak, P.; Tiruvalam, R.; Jenkins, R.L.; Carley, A.F.; et al. Facile removal of stabilizer-ligands from supported gold nanoparticles. Nat. Chem. 2011, 3, 551-556. [CrossRef] [PubMed]

32. Tanabe, K.; Misono, M.; Ono, Y.; Hattori, H. Studies in Surface Science and Catalysis; Fornasiero, P., Cargnello, M., Eds.; Elsevier: Amsterdam, The Netherlands, 2017; Volume 177, Chapter 1; p. 5.

(C) 2018 by the authors. Licensee MDPI, Basel, Switzerland. This article is an open access article distributed under the terms and conditions of the Creative Commons Attribution (CC BY) license (http:/ / creativecommons.org/licenses/by/4.0/). 